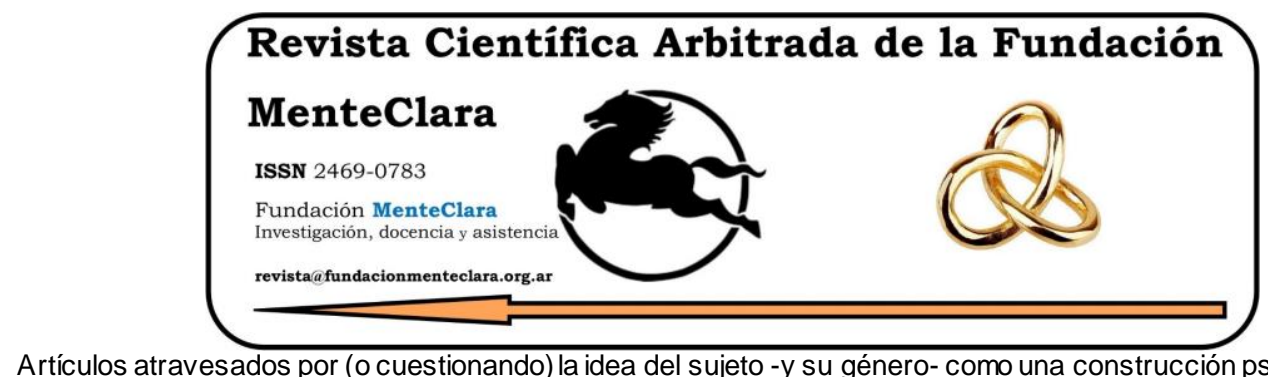

Artículos atravesados por (o cuestionando) la idea del sujeto -y su género- como una construcción psicobiológica de la cultura. Articles driven by (or questioning) the idea of the subject -and their gender- as a cultural psychobiological construction.

Vol. 7 (2022), enero-diciembre ISSN 2469-0783 https: / / datahub.io/ dataset/2022-7-e275

\title{
LA FUNCIÓN MATERNANTE DEL ANALISTA ANTE EL DESVALIMIENTO Y EL DESAMPARO FRENTE AL IMPACTO DE LO DISRUPTIVO: CONSIDERACIONES ACERCA DE LA TÉCNICA
}

THE MATERNAL FUNCTION OF THE ANALYST IN THE FACE OF HELPLESSNESS AND HELPLESSNESS IN THE FACE OF THE IMPACT OF THE DISRUPTIVE: CONSIDERATIONS ABOUT THE TECHNIQUE

Maria Pia Isely iselymariapia@yahoo.com.ar Universidad del Salvador, Lic. En Psicología, Doctorado Usal Apa, Argentina.

Cómo citar este artículo / Citation: Iseley, M. P. (2022). La función maternante del analista ante el desvalimiento y el de samparo frente al impacto de lo disruptivo: conside raciones acerca de la técnica. Revista Científica Arbitrada de la Fundación MenteClara, Vol. 7 (275). DOI: https://doi.org/10.32351/rca.v7.275

Copyright: (C) 2022 RCAFMC. Este artículo de acceso abierto es distribuido bajo los términos de la licencia Creative Commons Attribution 4.0 International License (CC BY 4.0). Recibido: 02/03/2022. Aceptado: 06/03/2022 Publicación online: 08/03/2022

Conflicto de intereses: Ninguno que declarar.

\section{Resumen}

El objetivo de este trabajo es realizar una revisión de la literatura psicoanalítica a través de una búsqueda bibliográfica sobre el papel del Analista ante el desvalimiento y el desamparo. Se intentará reflexionar acerca de la posibilidad de una función maternante del Analista como recurso técnico, dentro del Psicoanálisis para enfrentar el desvalimiento y el desamparo en la actualidad, el alcance y sus limitaciones. Para ello, se utilizó Google Académico, y la biblioteca de APA (Asociación Psicoanalítica Argentina), incluyendo artículos, libros, tesis de maestría y tesis doctorales publicados entre año 1970 y 2020, en idioma español. Los criterios de búsqueda incluyeron las palabras función maternante del analista ante el desvalimiento y desamparo, y luego reducida a los trabajos que referían a función maternante, desvalimiento y desamparo como conceptos separados. Los datos indicaron que es mucho lo que se ha escrito sobre el desamparo en especial en los últimos 10 años, 
sin embargo no es tanto lo que se ha encontrado sobre la función maternante como recurso técnico indicado, según los materiales investigados. Aun así se está investigando el vínculo temprano de la díada madre-hijo para ser reeditado en la diada paciente-terapeuta dentro de un psicoanálisis actual y contemporáneo en especial frente al desamparo actual Se concluye que es un tema a revisar en función de la ética y los riesgos del exceso que tal vez limiten el desplegué de este recurso terapéutico pata incluirlo dentro de la praxis psicoanalitica.

\section{Abstract}

The objective of this work is to carry out a review of the psychoanalytic literature through a bibliographic revision on the role of the Analyst in the face of isolation and helplessness. We will try to reflect on the possibility of a maternal function of the Analyst as a technical resource, as well as to identify the technical resources offered by Psychoanalysis to face the isolation and helplessness at present, the scope and limitations of this possible technical resource. For this reason, Google Scholar and the library of APA (Argentine Psychoanalytic Association) were used, including articles, books, master's theses and doctoral theses published between 1970 and 2020, in Spanish. The search criteria included the words maternal function of the analyst in the face of isolation and helplessness, and then reduced to the words that referred to maternal function, isolation and helplessness. The data indicated that much has been written about helplessness especially in the last 10 years; however, it is not so much, what has been found about maternal function as the most indicated technical resource according to the materials investigated. Even though, the early link of the mother-son dyad is being investigated, to be republished in the patienttherapist dyad within a current and contemporary psychoanalysis especially in the face of current helplessness. It is concluded that it is a topic to be reviewed in terms of ethics and the risks of excess that may limit the deployment of this therapeutic resource to include it within psychoanalytic praxis.

Palabras Claves: Psicoanálisis; función maternante; técnica; de svalimiento; de samparo

Keyw ords: Psychoanalysis; maternal function; technique; impotence or isolation;

helplessness 


\section{Introducción}

En los últimos años se ha incrementado notablemente las consultas psicológicas en torno a la salud mental; trastornos psicosomáticos, ataques de pánico, anorexia y bulimia, adicciones, trastornos del espectro autista, por el contrario, el Psicoanálisis dejó de recibir consultas y los pacientes se inclinaron a las terapias breves o al incremento de psicofármacos para encontrar una salida rápida al dolor. Sin embargo frente a esta nueva realidad actual es necesario que el mismo Psicoanálisis se replantee la técnica. El desamparo generalizado también atañe a los psicoanalistas que serán ellos que debieran buscar respuestas teórico técnicas para responder a la demanda; o bien; necesidad actual- El mismo Psicoanálisis comienza a plantearse la necesidad de un cambio en la técnica. En el último Simposio de la APA. (2018), Virginia Ungar - presidenta de la IPA International Psycoanalitical Association- se plantea: “¿Cuán preparados estamos para afrontar el alto

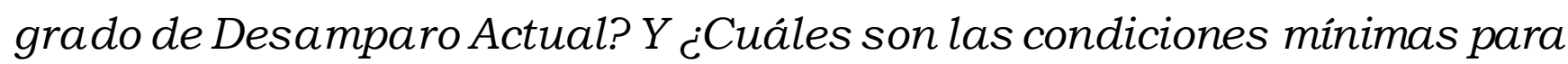
que una praxis se transforme en Psicoanalitica?”.

Si el psicoanálisis plantea una escucha de inconsciente a inconsciente y donde el hacer consciente lo inconsciente es su principal recurso técnico ¿cómo trabajar con aquellos pacientes que llegan a la consulta con un alto grado de desamparo y desesperanza?, pacientes arrasados frente a la muerte de un ser querido o un cáncer o la pérdida de trabajo, o con un ataque de pánico luego de haber tenido un robo a mano armada. Incluso desamparo frente a la falta de auxilio ajeno en el momento de dichos impactos disruptivos que no necesariamente serán traumatogénicos. A este tipo de impactos los denominaremos Impactos Disruptivos desarrollados por el DR, Benyakar (2005). 


\section{Lo Disruptivo}

Lo Disruptivo es la cualidad de situaciones o fenómenos fácticos que impactan en el psiquismo, provocando desestabilización, desregulación y/o desarticulación del funcionamiento psíquico. Estas transformaciones pueden ser elaborables y productivas para el psiquismo, como así también pueden provocar disturbios en el procesamiento psíquico, generando entre otras cosas, desvalimiento y desamparo (Benyakar, 2005).

Frente al impacto de lo Disruptivo de lo Fáctico sobre lo Psíquico en algunas ocasiones el paciente, y aun así el entorno, queda arrasado por efecto de una magnitud y se producen descargas como hemorragias al modo cuantitativo sin posibilidad de elaboración.

Frente a esta dificultad de elaboración el Psicoanálisis se replanteará cuál será allî la función del Analista

En función de esta revisión bibliográfica se intentará investigar la Función Maternante como recurso técnico psicoanalítico ante el desvalimiento y el desamparo producido por impactos disruptivos. Que en más de una ocasión desencadenan en estructuras psicosomáticas o narcisistas.

El trabajo con niños nos ha llevado a comprender de otra manera el trabajo con adultos narcisistas o psicosomáticos, trabajando desde el vínculo intersubjetivo con el Holding de Winnicott (1969) y la función de Reviere materna de (Wilfred, 1966). Pacientes narcisistas y/o psicosomáticos que acercaremos a lo que denominaremos como la clínica del Desamparo. 


\section{E1 desamparo}

Pasaremos a redefinir el Desamparo desde la literatura psicoanalítica:

Se referirá al Desamparo desde el Hilflosigkeit de Freud, que en la traducción de Amorrortu (1976) se expresa como desvalimiento, mientras que Pontalis (1994) en el diccionario de Psicoanálisis lo traduce como Desamparo; Estado de desamparo, refiriéndose a la impotencia del recién nacido, que es incapaz de emprender una acción coordinada y específica, remitiéndose al desamparo motor, motorische Hilflosigkeit. Que necesita de los cuidados maternos. Luego agrega que, desde el punto de vista económico, tal situación conduce al incremento de necesidad, que el aparato psíquico es incapaz de dominar: psychiche Hilflosigkeit: Desamparo Psíquico.

"El estado de desamparo; inherente a la dependencia total del pequeño ser con respecto a su madre, implica allí la omnipotencia de ésta. Influye asi en forma decisiva en la estructuración del psiquismo, destinado a constituirse enteramente en la relación con el otro" (Pontalis, 1994).

Dentro de la teoría de la angustia, para Laplanche (1994), el desamparo es el prototipo de la situación traumática. Benyakar (2005) definirá el desamparo como trauma, desligadura de afecto y representación. Más allá que él diferencia vivencia de desvalimiento de vivencia de desamparo. Y se remitirá a la vivencia de desamparo, cuando aquellos otros, incluyendo organismos estatales en los que uno confia que debieran amparar, desamparan al sujeto, por ejemplo, como ocurrió en el corralito o en los damnificados de Malvinas, en su regreso de la guerra.

Ahora bien, como la clínica se inclinaba más a patologias psicosomáticas y narcisistas tanto en niños como adultos, y al no alcanzar con los recursos técnicos del Psicoanálisis tradicional, cuyo 
principal objetivo era hacer consciente lo inconsciente, nos preguntamos cómo trabajar con aquellos pacientes donde el afecto está desligado de su representación, o bien presentan alexitimia o se encuentran al modo de $\mathrm{P}$, Marty en un pensamiento operatorio.

\section{Función maternante y maternalización}

Sin caer en el maternaje y diferenciándolo de la Maternalización (Laplanche 1996) se rescatará la importancia de la función maternante del analista, que pueda ligar el afecto con la representación, que permita el pasaje del narcisismo primario al secundario, y que ponga palabras al dolor sin nombre para que pueda transformarse en sufrimiento y desde allí de paso a la elaboración.

"Maternalización: Maternage. Mothering.: Técnica de psicoterapia de las psicosis, especialmente de la esquizofrenia, que tiende a establecer, entre el terapeuta y el paciente, de un modo tanto simbólico como real, una relación análoga, a la que existirá entre una madre y su hijo". (Laplanche y Pontalis, 1994)

La técnica de Maternalización se basa en una concepción etiológica de las psicosis que relaciona esta enfermedad con las frustraciones precoces, sobre todo orales, sufridas por el sujeto en su primera infancia. Técnica sobre todo reparadora "representa ante todo una comprensión de las necesidades fundamentales" (Laplanche y Pontalis, 1994). Estos autores, en el Diccionario de Psicoanálisis, mencionan que Racamier va a enfatizar en reconocer las necesidades básicas subyacentes a las defensas psicóticas y sobre todo responder a éstas en forma distinta a la interpretación clásica. 
En los últimos 20 años según estos autores desde Pontalis (1994) la maternalización exige del terapeuta más que una actitud maternal un verdadero compromiso afectivo, Y agrega:

"La relación de maternalización nace del encuentro entre un paciente profunda y vitalmente ávido de ser pasivamente colmado de satisfacciones, y un terapeuta que no sólo sea capaz de comprenderlo sino que además sienta el deseo de ir hacia él como una madre hacia un niño abandonado". (Laplanche y Pontalis 1994, p. 221)

La función Maternante que se intenta investigar en esta revisión bibliográfica vendría a cualificar esa excitación libre que ha quedado desligada del afecto. Intentando proporcionar un salto cualitativo tanto desde lo individual, con los pacientes en el consultorio, como desde lo social frente a la mirada de los Políticos, Educadores, Médicos, Sacerdotes. Así como la madre humaniza al infans en su Desamparo Primario la propuesta sería que la Función Maternante del auxilio ajeno humanizaria al paciente en su desamparo traumático. Restableciendo el principio de placer regulador y brújula de la vida psíquica. Que se extendería a los agentes externos, esos Otros Significativos que, al amparar, humanizarian a la sociedad desde lo que se denominará: la Función Maternante.

\section{Consideraciones acerca de la técnica}

Por los pacientes que hoy se acercan a los consultorios tan cercanos a las Neurosis Actuales, pacientes desamparados sobrecargados de Qn energética (Freud 1989) sin posibilidad de tramitación y con necesidad de una escucha diferente que pueda revisar la técnica. Mc Dougall (1978) dirá en "Alegato de una cierta anormalidad" que Freud al referirse a las 
neurosis actuales y pensar que estaban desprovistas de lo simbólico, no se hallaban encuadradas dentro de los alcances de la terapia psicoanalítica.

Sin embargo, con los aportes de los psicoanalistas contemporáneos se intentará rever a través de la revisión bibliográfica qué autores remiten a la técnica en tanto inversa al psicoanálisis clásico como diría Mc Dougall (1978) "Mientras que la conversión histérica asistimos al "salto misterioso" de la mente al cuerpo, el concepto de neurosis actuales implica un salto en la dirección opuesta de lo somático a la esfera psíquica”.

Mc Dougall (1978) en Alegato de una cierta anormalidad se remite al paciente psicosomático y se cuestiona cuáles son los límites del proceso analítico, pacientes con renegación, forclusión y escisión que se sirven como defensas para excluir los hechos psíquicos de la cadena simbólica, en especial todo lo que es proclive a producir dolor psíquico. Y dice "En ciertas situaciones privilegiadas podremos "oír" por lo menos señales de malestar". Como dice Tesone tal vez como señales de alarma de que algo no está funcionando bien, qué te duele, se preguntará el analista, tal vez, detrás de la enfermedad psicosomática del paciente. Continúa Mc Dougall; "Entonces comprenderemos que estos signos indican un dolor profundo que no puede ser reconocido por completo por el individuo en tanto persona que lo sufre". Aquello que denominaremos el dolor del Desamparo.

Freud en "Inhibición Síntoma y Angustia" (1924) dirá “Llamaremos traumáticas a una situación de desvalimiento vivenciada". La apreciación de nuestras fuerzas en comparación con su magnitud, la admisión de nuestro desvalimiento frente al peligro realista y desvalimiento psíquico frente al peligro pulsional. Benyakar (2005) agregará que Desamparo aquí nombra la imposibilidad de tramitar la excitación. 
En Mas Allá del Principio de Placer (1920) Freud dice: “Veinticinco años de trabajo intenso han hecho que las metas inmediatas de la técnica psicoanalitica sean hoy por entero diversas que al comenzar. En aquella época, el médico dedicado al análisis no podía tener otra aspiración que la de colegir, reconstruir y comunicar en el momento oportuno lo inconsciente oculto para el enfermo. El psicoanálisis era sobre todo un arte de interpretación". Ahora bien a diferencia de Freud rescataremos tomando a Winnicott la importancia del Otro significativo en la construcción del psiquismo sano. Así como Benyakar (2005) que agregará que "tanto los objetos diferenciados co-metabolizadores como el discurso del conjunto son condicionantes, pero no determinantes". En algunas ocasiones los factores co-metabolizadores activan la violencia secundaria. La violencia primaria será la violencia operada por la interpretación de la madre en relación con el conjunto de las manifestaciones vivenciales del infans. La violencia Primaria en el esquema de Benyakar (2005) será la actitud maternante necesaria para la construcción del aparato psíquico. Winnicott (1959) hablará de la Madre suficientemente buena y Benyakar (2005) 1lamará madre no suficientemente buena a la violencia secundaria que Piera Castoriadus, en (Castoriadis-Aulagnier, 1977), mencionará ante los riesgos del exceso.

La función Maternante permitirá que el instinto se transforme en pulsión a partir de su accionar catectizante, erogenizandoal niño a partir de sus caricias, palabras, amor dirá Winnicott (1959), transformando de esta manera la necesidad en deseo con ese plus de placer al cual deseará regresar o irá en la búsqueda de aquel objeto que le provea placer y satisfaga su necesidad. Se remitirá al concepto de Función Maternante como un accionar catectizante en relación transformativo y/o metabolizante. 
Desde aquí es que el objetivo de este estudio será reconocer o bien redefinir el concepto de función Maternante del Analista como recurso técnico frente a la clínica del desamparo. Desamparo de la cría humana que necesita de los cuidados maternos, Desamparo como trauma, desligadura de afecto y representación y Desamparo frente a impactos masivos; guerras. Catástrofes, incluso la pandemia actual el Covid 19.

\section{Material y método}

Se realizó una búsqueda bibliográfica de 40 artículos, incluyendo libros, tesis de maestría, tesis doctorales y publicaciones en Revistas Psicoanaliticas.

La búsqueda se realizó en libros editados entre los años 1970 y 2022, los artículos buscados fueron de los últimos 10 años; el criterio de inclusión de los libros fue específicamente Psicoanalíticos, y en idioma español.

Las tesis de Maestría y Doctorales se buscaron a través del Google académico con el constructo función maternante del analista ante el desvalimiento y el desamparo. Sólo se encontraron 2 una mencionando la actitud maternante y otra sobre el desamparo.

Se excluyeron artículos sobre función materna como constructo. Y aquellos que no se remitían a la técnica psicoanalítica.

La búsqueda se realizó a través de los constructos: primero, la función maternante del analista ante el desvalimiento y el desamparo, y luego reducida a función maternante, desvalimiento y desamparo- por separado. Se utilizó Google Académico, y la biblioteca de APA, Asociación Psicoanalitica Argentina. 


\section{Discusión y Resultados}

Uno de los artículos más relevantes que se encontró fue del Dr. Banyakar (2002) sobre la función maternante en intervención en catástrofes.

Allí destaca La función mediatizadora del adulto y el medio ambiente, y dice:

"Entendemos que el psiquismo se estructura en un constante interjuego entre interioridad y exterioridad. El infante humano debe enfrentarse con la tarea psíquica de conocer paulatinamente las propiedades del objeto exterior. En momentos de constitución, los estimulos externos, heterogéneos al aparato, tiene un alto potencial traumatogénico, debido a que la capacidad metabolizadora del infans está aún en desarrollo. Es por ello que los adultos cumplen una función mediatizadora con la realidad que el niño enfrenta".

La función maternante, mediatizadora del adulto, posibilita la constitución de un Yo que tomará a su cargo la metabolización de lo originario a lo primario y luego a lo secundario, sosteniendo un continuo interjuego entre sensaciones propias y percepciones de estímulos provenientes del mundo externo (Aulagnier, 1977). La situación disruptiva se torna catastrófica, cuando el adulto no puede metabolizar lo acaecido, sufre una desubjetivización y cosificación, pudiendo perder su capacidad mediatizadora. Si esto ocurre, los niños vivencian lo externo como traumatogénico, aún sin haber asistido en forma directa al impacto del evento. En situaciones disruptivas parecería que se tiende a alentar la autonomía de los niños, negando el tiempo de metabolización y las necesidades de estos de ser protegidos por los adultos. La elaboración del desamparo y perpetuación del desvalimiento deberán estar en el foco 
de atención de todo equipo profesional que pretenda actuar en estas situaciones. Teniendo en cuenta que al dirigirnos a los niños estamos activando una parte atemorizada del niño que hay en nosotros, puesto que todos fuimos en alguna medida niños más o menos asustados (Winnicott, D. 1974, Benyakar, M. 1996b).

Lerner (2013) toma los aportes de Winnicott y Bowlby rescatando la importancia del otro significativo que cumpla en responder a las necesidades del sujeto adviniente, así como en los comienzos esto apunta a brindarle al bebe lo que necesita para no caer en un desamparo traumático, en una no-integración inicial (Winnicott 1945), estos suministros de otro significativo serán indispensables para el sujeto. "Sin otro no hay producción de subjetividad". Pág. 11 actualidad Psicológica.

En un artículo sobre el pensamiento clínico contemporáneo, Uribarri va a decir que en la IPA se está estudiando el rol del objeto primario en la constitución y funcionamiento del psiquismo temprano desde una perspectiva genética o evolutiva. Introduce dice él una suerte de tercera tópica centrada en la relación entre el self y el objeto. En este marco revaloriza el rol del objeto en la clínica, modificando por lo tanto la técnica y explorando la dimensión materna de la transferencia -y la contratransferencia-. Un nuevo esquema dual referido a la relación temprana diádica madre-bebe, marcará la teoría y la clínica.

En este mismo artículo agrega que se postula que la identificación proyectiva-Klein- es percibida mediante afectos contra transferenciales por el analista, quien se encarga de contenerlos y significarlos del mismo modo en que la madre lo hace con los impulsos y la comunicación preverbal del bebe "reviere materno".

Extendiendo al análisis en general las modificaciones técnicas surgidas en el tratamiento de niños y pacientes psicóticos, la 
interpretación deviene interpretación de la transferencia en el aquí-ahora conmigo.

"El funcionamiento del analista tiende a identificarse con la función materna (según el esquema dual madre-bebe). Al eje identificaciónproyectiva contratransferencia corresponde un ideal técnico de analista "continente".

Farias (2005) presenta pacientes arrasados por la angustia automática, sujetos que no presentan un síntoma clásico sino un goce silencioso. Desde un abordaje lacaniano. Pacientes en desamparo social, vincular, cultural y simbólico y se preguntan si es factible de una operación analítica.

Saraceno (2015) destaca la importancia del objeto, en tanto otro, en la estructuración del psiquismo. En concordancia con los autores destacados de nuestra temática, Bion con su reverie materna, Winnicott con su holding, Green, entre otros.

Oleaga en Desnutrición simbólica y desamparo desarrollan la noción de desamparo en la obra de Freud en una articulación entre dolor y placer y toman las herramientas de Freud como instrumentos válidos para pensar hoy el malestar contemporáneo.

Rendo, (2012) desarrolla una articulación entre desamparo e inconsciente para ellos ambos se atraviesan en función del ser y van a destacar la relación con el otro como elemento capaz de tramitar el desamparo psíquico.

Canteros, (2021) En este libro plantea la clínica del desamparo como la clínica actual en un interjuego entre Freud Lacan y Winnicott como perspectiva para pensar tanto la clínica actual como el desamparo sociocultural. 
También se ha encontrado que el Método madre canguro (MMC) es una técnica de atención del neonato en situación de bajo peso al nacer y/o prematurez que se fundamenta en el contacto piel a piel entre la madre y el bebé y los cuidados que en alimentación, estimulación y protección que aquella provee a este.

El contacto piel a piel también puede ser brindado por el padre u otro adulto. El MMC cubre eficazmente las necesidades de los neonatos en calor, alimentación -lactancia materna-, protección frente a infecciones, estimulación, seguridad y amor, siendo su eficacia similar, e inclusive superior en determinadas circunstancias, que los cuidados tradicionales -i.e. incubadora o radiadores de calor- si se comparan en términos de mortalidad y morbilidad.

Así mismo, reduce significativamente la estancia hospitalaria y los costos del cuidado de los neonatos con bajo peso al nacer. Su indicación principal está dada en neonatos estables, es decir, aquellos que pueden respirar por sí mismos y no cursan con enfermedades graves. Su nombre se deriva de la similitud de esta técnica con el desarrollo extrauterino que realizan los canguros neonatos -y en general todos los marsupiales-, los cuales después de salir del útero terminan su desarrollo agarrados de las glándulas mamarias que se encuentran al interior de la bolsa marsupial o marsupio de la madre.

Nemirovsky en 1999 y 2009, realiza una amplia revisión de las perspectivas de Winnicott y Kohut en torno a los fenómenos iniciales de la vida psíquica, con el propósito de aportar herramientas para la comprensión de la constitución de las estructuras psíquicas del adulto. Y agregará que si el paciente confia en el comportamiento del analista, podrá recrearse la situación traumáticamente interrumpida. Pacientes que necesitarán de un cuidadoso encuadre, capaz de poder brindarles, 
una metáfora, sustituto de los "cuidados maternos", posibilitando así una novedosa "edición" (Nemirovsky, 2018).

Margaret Mahler (1977) hablará sobre la función catalizadora de la maternación normal. A fines de la década de 1950, en el Master's Children Center de Nueva York, comienzan a trabajar con simbiosis psicótica infantil y desarrollan el método de "relación simbiótica correctora" entre la madre y el niño mientras el terapeuta actuaba como un puente entre ellos.

Conjuntamente con Mahler (1977) y otros, otorgan al medio ambiente prioridad sobre lo instintivo; Winnicott (1959) postulando la necesidad por parte del niño de objetos que lo sostengan ambos incidiendo en que es en la respuesta fallida de los objetos a las necesidades del infante donde reside el origen de la patología, o bien del desvalimiento.

Nemirovsky (2018) retoma el concepto de desvalimiento psíquico Hilflosigkeit desarrollado por Freud en "Inhibición, síntoma y angustia" (1926) y describe la clínica como angustia de fragmentación, de dejar de ser, de desaparecer sin previa señal, vivencias de vacío y de irrealidad, frente a las que se ponen en juego una serie de mecanismos conducentes al sobrevivir.

También retoma Nemirovsky (2018) al igual que Benyakar, Lezica (2005) el concepto de trauma partiendo de la definición de Laplanche y Pontalis (1968):

“... un acontecimiento en la vida del sujeto caracterizado por su intensidad, la incapacidad del sujeto de responder a él adecuadamente y el trastorno y los efectos patógenos duraderos que provoca en la organización psíquica. En términos económicos, el traumatismo se caracteriza por un aflujo de excitaciones excesivo, en 
relación con la tolerancia del sujeto y su capacidad de controlar $y$ elaborar psiquicamente dichas excitaciones".

En el estudio de la histeria, el origen del trauma permanece limitado a lo sexual: un acontecimiento infantil es reactivado retroactivamente après-coup- con la eclosión de la sexualidad puberal. Y en los desarrollos metapsicológicos, es el carácter mismo de la vida fantasmática lo que predispone al trauma, es por ello que allí se trabajará haciendo consciente lo inconsciente más ligado a las fantasías.

Deprati (2007) escribe un artículo donde analiza las ideas de diferentes autores en función del desamparo entre ellos recoge el pensamiento de Ferenczi (1933) que, en base a lo postulado por Freud, plantea el trauma como resultado de "la falta de respuesta adecuada del objeto ante una situación de desamparo"; concepción novedosa, dice el autor, que no consigue hacerse un lugar en la teorización psicoanalítica por la relevancia que en aquellos años tiene la fantasía en la vida psíquica. Subraya también la posición de Winnicott (1959) -evidentemente, para el autor, fundamental en el trabajo con perturbaciones severas- cuando dice:

“... el término regresión tiene ahora una aplicación clínica en la regresión a la dependencia [...] la regresión es vista como parte de la capacidad del individuo para producir su auto curación. Representa una indicación del paciente al analista acerca de cómo debe comportarse este último, más bien que a cerca de cómo debe interpretar al paciente [...] la regresión representa la esperanza del individuo psicótico de que puedan revivirse ciertos aspectos del ambiente que originalmente fallaron, pero revivirlos de un modo tal que en lugar de 
fallar en su función de desarrollary madurarla tendencia heredada, esa vez tenga éxito".

Luego, a partir de una cita de Winnicott (1960 b) se propone reflexionar sobre algunos puntos que destaca:

“... el analista está preparado para aguardar hasta que el paciente sea capaz de presentar los factores ambientales en términos que permitan su interpretación como proyecciones. En un caso bien escogido, este resultado surge de la capacidad del paciente para confiar, que es redescubierta en la confiabilidad del analista y en el encuadre profesional. A veces el analista tiene que esperar mucho y en el caso mal elegido para el psicoanálisis clásico es probable que la confiabilidad del analista sea el factor más importante lo más importante que las interpretaciones) porque el paciente no la experimentó en el cuidado materno de la infancia y para poder hacer uso de ella necesitará encontrarla por primera vez en la conducta del analista”.

“... reflejar, dar coherencia, significary discriminarla emoción, comprender la secuencia del material manifiesto y no rechazarlo como poco valioso o que lo es sólo en la medida en que es el vehículo del cual se sirve lo inconsciente para emerger, poner limites ('a usted no le conviene'...), o dar alguna sugerencia ('Mejor postergaresa decisión para más adelante')" (Deprati, 2007).

“Tenerpaciencia y tolerar no interpretartodolo que percibimos, permitir la intimidad del paciente consigo mismo, siendo, por momentos, testigos mudos de nuestra propia exclusión”. (Lerner y Nemirovsky, 1989).

Winnicott sostiene que el encuadre es una herramienta terapéutica particularmente significativa en el tratamiento con pacientes cuyo 
sufrimiento deriva de traumas tempranos y se aleja de la postulación freudiana de hacer consciente lo inconsciente aduciendo el riesgo de adoctrinamiento que implica formular una interpretación sin tener en cuenta el nivel de regresión del paciente.

Conde desarrolla el concepto de "función cometabolizadora" de Benyakar (2005) y rescata los aportes de Piera Alaugnier mencionando el concepto de: "relación maternante". Este concepto dice el autor refiere a la alteridad, es decir a la capacidad de ponerse en lugar del otro, como también poder comprender a ese otro. Esta "alteridad" colabora en el proceso de elaboración ante el desvalimiento que puede surgir en la psiquis del niño

De Oliveira Liger en su tesis sobre el desamparo dice: "El desamparo es un estado de impotencia que el ser humano enfrenta ante el dolor psiquico y según Freud, el sufrimiento puede deberse a tres situaciones diferentes: a la decadencia del propio cuerpo que lleva a la muerte; frente al mundo externo $y$ sus fuerzas destructivas $y$, finalmente, en las relaciones con sus semejantes". Y menciona que la palabra desamparo aparece en la literatura psicoanalítica desde casi sus comienzos. En el texto " Proyecto de una psicología científica", Freud dice: " El desamparo original del hombre es la fuente primordial de todos los motivos morales" (Freud, 1895), pero sólo a partir de 1915 en adelante, la palabra adquiere una conceptualización en los escritos de Freud y agrega que en las últimas décadas, la palabra desamparo comenzó a aparecer con mucha frecuencia en el discurso psicoanalítico, significando una estructura psíquica cuya esencia es el vacío. Estudios recientes publicados por el psicoanalista argentino Dr. David Maldavsky toman el término desvalimiento, traducido al español por la editorial Amorrortu, para especificar esta estructura psíquica. 
El objetivo de este estudio realizado por De Oliveira Liger fue correlacionar el desamparo /desvalimiento con los cambios de paradigma de la postmodernidad y articularlo con las ideas de Maldavsky sobre el desvalimiento.

Lic. Daniela Gastaldi se cuestiona el Maternar como función del analista y toma a Winnicott:

"Donald Winnicott describe funciones inherentes al quehacer materno que permiten la emergencia del desarrollo emocional primitivo del bebé. Dá particular importancia al sostén, como aquel eje fundamental desde el cual el bebé irá logrando integrar su self."

Dice la autora.

En este breve recorte seleccionado de un artículo publicado en 1960 La pareja madre-lactante-, realiza un paralelismo de la función materna con la función del analista:

"La tesis que propongo aqui es que lo que hacernos en la terapia equivale a un intento de imitar el proceso natural, que caracteriza la conducta de cualquier madre con respecto a su propio bebé. Si estoy en lo cierto, la pareja madre-bebé es la que puede proporcionarnos los principios básicos para fundamentar nuestra labor terapéutica, cuando tratamos niños cuyo temprano contacto con la madre fue deficiente o se vio interrumpido..."

Yago (2020) Franco desarrolla un artículo en página 12 en función de la Pandemia y la cuarentena e investiga Las respuestas psiquicas que produce la suspensión de la realidad socialmente instituida y la creación de otra, precaria e incierta ha producido, vinculándolo específicamente con el Hilfosigkeit de Freud. Y también se cuestiona El papel de los analistas en esta crisis en desarrollo. 
Este autor se cuestiona cómo abordará el Psicoanálisis esta clínica actual producto de la Pandemia. Pero no relaciona la función del analista como función Maternante.

Gerard Gillerault (2009), en "Dolto/Winnicott, El bebé en psicoanálisis» Rescata Las diferencias entre Doltó y Winnicott y su enfoque terapéutico rescatando la regresión en ambos autores uno a una relación de dependencia otro a la imagen del cuerpo, y se preguntará sobre si es Psicoanálisis, Psicología o bien una Psicología del desarrollo. Allí dice referenciando a Winnicott: "Sin lugar a dudas, esto coloca al analista en una posición que debemos llamar "maternante", desde el momento en que en efecto "el marco del psicoanálisis reproduce las técnica de maternaje" haciéndose cargo no del deseo sino de las necesidades del paciente".

Benyakar Lezica (2005) en "Lo traumático, Clínica y paradoja» Tomo 1 y 2. Desarrolla el concepto de vivencia de desamparo y su abordaje terapéutico, rescatando la función maternante especialmente como función co metabolizadora.

Ferenczi Sandor (1933) destaca la función maternante que la biologia cumple en el ser humano y su aplicación técnica en el análisis de sus pacientes en desamparo con la terapia activa y el análisis mutuo, a fin con nuestra temática planteada.

Green (2005) en "Jugar con Winnicott" rescata a Winnicott con su preocupación maternal primaria, sus diferencias con Klein y con Freud en el abordaje terapéutico. Green dirá que el analista "es" la madre en 
determinados pacientes. Aunque critica a Winnicott en ser excesivamente maternante, nombrándolo como terapia de "bondad".

"El principal reproche que yo haria a Winnicott es el haber creido en el deber incondicional en representar una madre suficientemente buena para los pacientes, y en cierta medida, haber creado esa imagen" (Green, 2005)

\section{Conclusiones}

A lo largo de nuestra investigación y revisión bibliográfica se han encontrado un alto porcentaje de artículos -de los 40 revisados-, refiriendo especialmente al desamparo y al desvalimiento en Psicoanálisis, no así a la función Maternante del Analista como recurso técnico, entendemos que es un término controvertido para ser revisado en función de la ética por los riesgos del exceso.

Los datos indicaron que es mucho lo que se ha escrito sobre el desamparo en especial en los últimos 10 años, sin embargo no es tanto lo que se ha encontrado sobre la función maternante como recurso técnico más indicado según los materiales investigados. Aun así se está investigando el vínculo temprano de la díada madre-hijo para ser reeditado en la diada paciente-terapeuta dentro de un psicoanálisis actual y contemporáneo en especial frente al desamparo actual .Se concluye que es un tema a revisar en función de la ética y los riesgos del exceso que tal vez limiten el despliegue de este recurso terapéutico pata incluirlo dentro de la praxis psicoanalítica.

Freud a lo largo de su obra no menciona la función Maternante, sî hablará del auxilio ajeno (Freud, 1989) pero no remitiéndose a la técnica, Ferenczi (1933) comienza a esbozar el término función Maternante y junto a Winnicott (1959) con su preocupación maternal primaria realizarán un cierto giro en la técnica, en especial Ferenczi con sus 
pacientes en desamparo o traumatizados y Winnicott con los pacientes no-neuróticos.

Igualmente entendemos que según esta revisión la función maternante es un término contemporáneo para repensar la técnica actual, en especial ante el desvalimiento y el desamparo frente a impactos disruptivos; incluso del Covid y la Pandemia Actual.

Por todo lo expuesto quisiéramos destacar la relevancia científica de este estudio de revisión bibliográfico con la intención de recatar los aportes técnicos que puedan servir tanto a la técnica como a la prevención en situaciones de desamparo psíquico ya sea en el vínculo temprano madre- hijo trabajando en la prevención, así como en los pacientes que han sufrido situaciones de impacto masivo que llevan al desamparo psíquico en un avance en la técnica psicoanalitica con estos pacientes que en los últimos años se han llamado pacientes dificiles para los terapeutas. Ofreciendo la función maternante como recurso técnico que atienda la necesidad más que el deseo, transferible tanto a los terapeutas como docentes, profesionales de la salud y aún políticos. 


\section{Referencias}

Benyakar, M Lezica, A. (2005). Lo traumático, Clínica y paradoja”. Editorial Biblos. Buenos Aires.

Canteros N (2021). «El cuerpo en la experiencia psicoanalítica. Entre Freud, Lacán y Winnicott» Bs. As.

Castoriadis-Aulagnier, P. (1977). La violencia de la interpretación. Buenos Aires: Amorrortu.

Deprati, D. (2007). Winnicott y Kohut. Nuevas perspectivas en psicoanálisis, psicoterapia y psiquiatria. La intersubjetividady los trastornos complejos [Nemirovsky, C., 2007]. Aperturas psicoanalíticas: Revista de psicoanálisis, (27), 11.

Desamparo y separación - Acta Académica por ME Domínguez · 2011 - Internacional de Investigación y Práctica Profe sional en Psicología XVIII. Desamparo y separación: algunas consideraciones a partir de un caso de apropiación [En línea] https://www.aacademica.org/000-052/745.pdf

Desnutrición simbólica y desamparo - EL PSICOANALITICO | Publicación de Psicoanálisis. [En línea] https:/ / www.elpsicoanalitico.com.ar/num3/subjetividad-oleaga-de snutricion-simbolicadesamparo.php

El desvalimiento como sintoma de la Postmodernidad. De cómo la contemporaneidad evoca el de svalimiento" Unidad Temática: Teoría Olivan DE OLIVEIRA LIGER [En línea] http://www.fepal.org/wp-content/uploads/0088.pdf

El psicoanalista ante el desamparo social - Acta Académica por F Farías · 2005 · [En línea] https://www.aacademica.org/000-051/354.pdf

El sujeto a la intemperie. La cuestión del desamparo en Freud y en Lorca por M del Carmen Rodríguez-Rendo $\cdot 2012$ [En línea] https://dialnet.unirioja.es/descarga/articulo/3910976.pdf

Ferenczi, S. (1933). Problemas y métodos del Psicoanálisis. Ediciones Horme

Freud, S (1989). "Proyecto de Psicología para neurólogos" Amorrortu editores 2012 Buenos Aires.

Freud, S (1920). "Mas allá del principio de placer" Amorrortu editores 2012 Buenos Aires.

Freud, S (1925-1926). Tomo XX "Inhibición Síntoma y Angustia" Amorrortu editores 2012 Buenos Aires.

Freud, S (1925-1926). Tomo XX "Inhibición Síntoma y Angustia" Amorrortu editores 2012 Buenos Aires.

Gerard Gillerault (2009). Dolto/Winnicott. EL Bebé en el Psicoanálisis. Ed. Paidós Psicología Profunda.

Winnicott, D. (1956/1979). Preocupación maternal primaria en Escritos de Pediatría y Psicoanálisis. Editorial Paidos. Psicología profunda.

Gillerault, G. (2009). Dolto/Winnicott., El bebé en psicoanálisis. Ed. Paidós Psicología Profunda 2009 Bs, As, Argentina-.

Green, A (2005). Jugar con Winnicott. Amorrortu editores 2012, Buenos Aires.

La disponibilidad del analista por S Saraceno Fasce · 2015 Maestría en Psicoanálisis USAL-APA [En línea] https:/ / racimo.usal.edu.ar/4293/1/P\%C3\%A1ginas\%20desde 500024475-

La\%20disponibilidad\%20de1\%20analista.pdf 
Laplanche, J y Pontalis, J. (1994). Diccionario de Psicoanálisis. Ed. Labor. Barcelona 1993.

Lerner, H. (2013). Felicidad, sufrimiento, realidad. ANO 2, NUMERO 1, JAN-JUN/2013 ISSN 22389083 (VERSÃO IMPRESSA) ISSN 2316-6010 (VERSÃO ONLINE), 27.

Mahler, M (1977). El nacimiento psicológico del infante humano. Simbiosis e individuación Ediciones Marymar. Bs. As. 1977

McDougall, J (1978). "Alegato de una cierta anormalidad" Ed Paidós Psicología Profunda 2004 Bs. As.

Nemirovsky C (2018). Psicoanálisis latinoamericano contemporáneo" Editorial APA. Argentina.

Sandor, F (1926/2009). Problemas y Métodos del psicoanálisis. Ediciones Horme, 2009, Bs. As.

Wilfred, B. (1966). Aprendiendo de la experiencia. Ed. Paidos - Psicologia profunda.

Winnicott, D. (1954c/1979). Aspectos metapsicológicos y clínicos de la regresión dentro del marco psicoanalítico en Escritos de Pediatría y Psicoanálisis. Editorial Laia.

Winnicott, D. (1956/1979). Preocupación maternal primaria en Escritos de Pediatría y Psicoanálisis. Editorial Gedisa.

Winnicott, D. (1967b/1979). Papel de espejo de la madre y la familia en el desarrollo del niño; en Realidad y Juego - Gedisa editorial - Barcelona 1979

Winnicott, D. (1969b/1991). La experiencia de mutualidad entre la madre y el be bé en Exploraciones Psicoanalíticas I. Editorial Paidós.

Yago (2020). https://www.pagina12.com.ar/261563-coronavirus-trauma-angustia-y-deseo 